BMJ Open

Diabetes

Research

\& Care

\section{Prevalence, awareness, treatment, and control of diabetes mellitus by depressive symptom severity: a cross-sectional analysis of NHANES 2011-2016}

To cite: Lee J, Kim KH, Ahn JC, et al. Prevalence, awareness, treatment, and control of diabetes mellitus by depressive symptom severity: a cross-sectional analysis of NHANES

2011-2016. BMJ

Open Diab Res Care

2021:9:e002268. doi:10.1136/

bmjdrc-2021-002268

- Supplemental material is published online only. To view, please visit the journal online (http://dx.doi.org/10.1136/ bmjdrc-2021-002268).

Received 13 March 2021 Accepted 11 May 2021
Check for updates

(c) Author(s) (or their employer(s)) 2021. Re-use permitted under CC BY-NC. No commercial re-use. See rights and permissions. Published by BMJ.

For numbered affiliations see end of article.

Correspondence to Dr Sang Min Park; smpark.snuh@gmail.com

\section{ABSTRACT}

Introduction Despite extensive studies on the relationship between diabetes mellitus (DM) and depression, the associations of depressive symptom severity with prevalence, awareness, treatment, and control of diabetes remain unclear. We aimed to investigate changes in these outcomes of diabetes as depressive symptoms aggravate. Research design and methods We conducted a crosssectional analysis of 14328 participants in the 2011-2016 National Health and Nutrition Examination Survey. Participants were classified into depressive symptom groups of none, mild, moderate, moderately severe, and severe depending on their Patient Health Questionnaire-9 scores. Multivariate logistic regression analyses were conducted in three models adjusted for expanding confounders to evaluate the associations between severity of depressive symptoms and prevalence, awareness, treatment, and control of DM.

Results As depressive symptom severity worsened, both prevalence and awareness of DM increased regardless of models ( $p$ value for trend $<0.01$ in all models for prevalence and awareness; adjusted OR (aOR) 2.14, $95 \% \mathrm{Cl} 1.29$ to 3.56 for prevalence in the severe group, model 1; aOR 2.43, 95\% $\mathrm{Cl} 1.27$ to 4.64 for awareness in the moderately severe group, model 1). Notwithstanding higher awareness of diabetes in the moderately severe and severe groups $(84.5 \%$ and $86.2 \%$, respectively, vs $71.3 \%$ in the none group), these groups were treated less (a0R $0.25,95 \% \mathrm{Cl} 0.11$ to 0.55 in the severe group, model 3 ) or inadequately controlled (aOR $0.51,95 \% \mathrm{Cl} 0.27$ to 0.98 in the moderately severe group, model 3).

Conclusions The gap between patients' higher awareness and lower treatment rate or control of diabetes among individuals with severe depressive symptoms highlights the unmet needs for postdiagnostic multidisciplinary care for patients with comorbid depression and DM.

\section{INTRODUCTION}

Diabetes mellitus and depression are two major public health concerns in the USA. According to the 2020 report by the Centers for Disease Control and Prevention (CDC),

\section{Significance of this study}

What is already known about this subject?

- Diabetes mellitus and depression have bidirectional causality through multilayered (biological, psychological, socioeconomic, and cultural) mechanisms.

- The burden of diabetes and depression has continuously increased among the US population and therefore their comorbidity is also a significant public health concern.

What are the new findings?

- As depressive symptoms worsened, prevalence and awareness of diabetes mellitus increased.

- Despite higher awareness of diabetes in the moderately severe and severe depressive symptom groups, their treatment and control rates were low compared with groups with less severe depressive symptoms.

- Unhealthy behavioral factors such as obesity, smok ing, and physical inactivity were more frequently observed in those with depressive symptoms.

How might these results change the focus of research or clinical practice?

- Our study emphasizes the fact that individuals with diabetes with moderately severe and severe depressive symptoms (Patient Health Questionnaire-9 score of 15 or higher) represent a unique patient group with an unmet need in the current care model.

- At a public health level, multidisciplinary approaches which incorporate care for both diabetes and depression should be implemented in chronic care models.

- At a practice level, physicians should consider the possibility of severe depression in a patient whose diabetes is poorly controlled despite optimal therapy.

more than 34 million people in the USA have diabetes, ${ }^{1}$ and in addition US adults with a past-year major depressive episode reached 
19.4 million in $2019 .^{2}$ On top of the burden of each disease, their comorbidity and bidirectional causality pose even greater challenges at both the individual and public health levels. ${ }^{3-5}$ A meta-analysis of prospective cohort studies summarized that there is a $60 \%$ increased risk of incident type 2 diabetes among individuals with depression and a $15 \%$ greater risk of incident depression among patients with diabetes over their life span. ${ }^{4}$ When broader designs of studies and patients with type 1 diabetes are included, the prevalence of depression among patients with diabetes doubles or triples compared with that among those without diabetes mellitus. ${ }^{36}$

Previous studies indicated that complex shared mechanisms in biological, psychological, socioeconomic, and cultural aspects contribute to the comorbidity of these two conditions. ${ }^{78}$ These multilayered associations also impact the clinical outcomes of each disease. A meta-analysis showed that depression was associated with hyperglycemia among people with type 1 or type 2 diabetes. ${ }^{9}$ Furthermore, there were strong associations between depression and diabetic complications such as retinopathy and neuropathy. ${ }^{10}$ Unsurprisingly, depression among those with diabetes significantly disrupted patients' quality of life. ${ }^{11}$ A randomized controlled trial revealed that specifically designed collaborative care for patients with diabetes and depression improved the level of glycated hemoglobin (HbAlc) and quality of life compared with usual care, ${ }^{12}$ and other care models that aimed at simultaneously managing the two conditions also showed promising results. ${ }^{1314}$

Although many researchers agree that specialized interventions are needed for patients with comorbid depression and diabetes, ${ }^{78}$ only a limited number of studies have looked into the relationship between the severity of depressive symptoms and diabetes-related clinical outcomes. ${ }^{515} 16$ In addition, while some studies investigated the combination of prevalence, awareness, treatment, and control of diabetes in different demographic groups, none has been conducted in conjunction with depression. ${ }^{17-19}$ Therefore, the aim of our study was to study the associations between depressive symptom severity and prevalence, awareness, treatment, and control of diabetes using the National Health and Nutrition Examination Survey (NHANES) data to identify specific subgroups that need specialized attention beyond usual care.

\section{RESEARCH DESIGN AND METHODS \\ Study population}

We conducted a cross-sectional study of the NHANES data from years 2011 to 2016. NHANES is a national survey conducted and released in a 2-year cycle by the CDC. It is unique in that it incorporates both interviews and physical examinations by highly trained interviewers and examiners.

The research sample comprised non-pregnant adults (aged 20 and older) who completed a depression screening questionnaire (Patient Health Questionnaire-9, PHQ-9) and underwent screening for diabetes with laboratory tests (fasting plasma glucose, HbAlc, plasma glucose 2 hours after $75 \mathrm{~g}$ oral glucose tolerance test) or a survey. Initially, 14581 adults who completed the PHQ-9 were selected. Of these, 163 pregnant participants, 76 with incomplete demographic or examination data (besides household income and body mass index (BMI)), and 14 with no available information regarding diabetes were excluded. Finally, 14328 participants were included in the analysis (figure 1).

\section{Definition of depressive symptom severity}

We used the PHQ-9 self-report questionnaire available within the NHANES data to determine the severity of patients' depressive symptoms. The PHQ-9 consists of nine questions which score each item of the Diagnostic and Statistical Manual of Mental Disorders-IV (DSM-IV) criteria for major depressive disorder. Participants were classified into five groups of depressive symptom severity according to the sum of the total raw PHQ-9 score: 0-4 (none), 5-9 (mild), 10-14 (moderate), 15-19 (moderately severe), and 20 or greater (severe). A PHQ-9 score of 10 or above is consistent with a diagnosis of major depression using the DSM-IV, with sensitivity of $88 \%$ and specificity of $88 \% .^{20}$

\section{Definition of prevalence, awareness, treatment, and control of} diabetes

Participants who met one of the following five criteria were considered to have diabetes: (1) fasting plasma glucose $\geq 126 \mathrm{mg} / \mathrm{dL},(2) \mathrm{HbAlc} \geq 6.5 \%(48 \mathrm{mmol} / \mathrm{mol})$, (3) post 2-hour plasma glucose after $75 \mathrm{~g}$ oral glucose tolerance test $\geq 200 \mathrm{mg} / \mathrm{dL}$, (4) self-report of previous diagnosis of diabetes by medical professionals, or (5) taking glucose-lowering agents or insulin (survey or prescription medication check). Criteria 1-3 were based on the diagnostic criteria of diabetes mellitus by the American Diabetes Association, ${ }^{21}$ and criterion 4 was based on a question in the NHANES diabetes survey, which asks participants 'Other than during pregnancy, have you ever been told by a doctor or health professional that you have diabetes or sugar diabetes?' Participants who answered 'yes' to this question were regarded as having diabetes. Criterion 5 was determined by survey questions that asked participants if they were taking insulin or oral glucose-lowering agents, or based on the examination of prescribed diabetic medications used in the past 30 days. Participants taking the following classes of medications were classified as having diabetes mellitus: biguanides, sulfonylureas, dipeptidyl peptidase 4 inhibitors, incretin mimetics (Glucagon-Like Peptide-1 agonists), thiazolidinediones, meglitinides, sodium-glucose cotransporter-2 inhibitors, alpha-glucosidase inhibitors, and all types of insulin.

With regard to the outcomes of interest among patients who met the above criteria for diabetes mellitus, awareness of diabetes was determined based on their answers to 
20 years or older adults in $\operatorname{NHANES}^{*}(\mathrm{n}=17,048)$

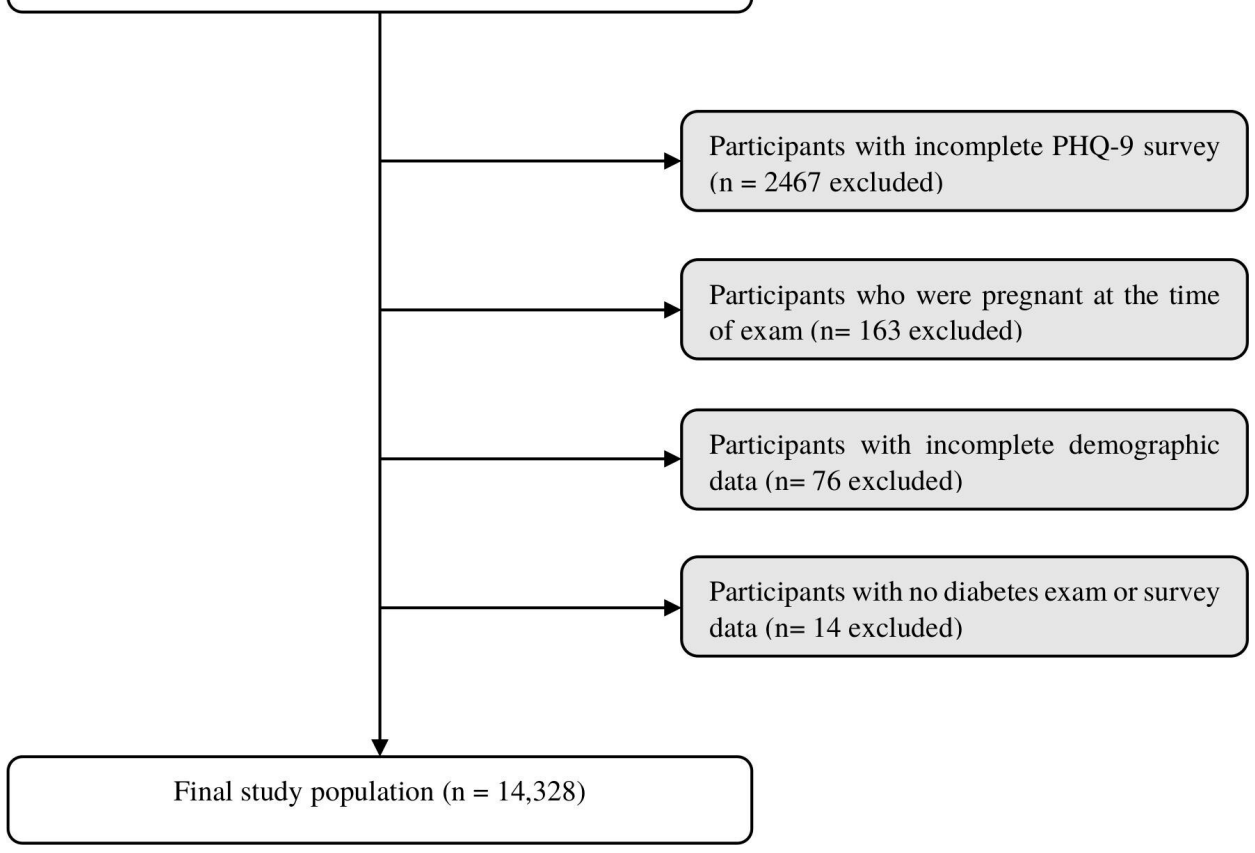

Figure 1 Flow diagram of selection of study population. *2011-2016 National Health and Nutrition Examination Survey (NHANES). PHQ-9, Patient Health Questionnaire-9.

criterion 4 (self-report of a previous diagnosis of diabetes by a medical professional); treatment for diabetes was defined based on criterion 5 (either self-report or documented evidence of taking glucose-lowering agents or insulin); lastly, the control of diabetes was defined as having $\mathrm{HbAlc}$ below $7 \%(53 \mathrm{mmol} / \mathrm{mol}) .{ }^{21}$

\section{Associated factors}

Given the complex association between depression and diabetes, we analyzed our models with three major categories of covariates including demographic, behavioral, and socioeconomic factors. The demographic factors included age, sex, and race/ethnicity. The behavioral factors included BMI, smoking, alcohol consumption, and physical activity. Participants were classified according to BMI into underweight $(\mathrm{BMI}<18.5)$, normal $(18.5 \leq \mathrm{BMI}<25)$, overweight $(25 \leq \mathrm{BMI}<30)$ and obese $(\mathrm{BMI} \geq 30)$ groups, and those with missing BMI values were assigned to the unknown group. Smokers and ex-smokers who reported 'yes' to the question 'Have you smoked at least 100 cigarettes in your entire life?' were grouped together as eversmokers. In addition, those who reported one or more days of excessive drinking (five or more drinks in men and four or more drinks in women) in the past 12 months were considered to be in the binge drinking group. ${ }^{22}$ Individuals who reported that they were engaged in moderate or vigorous recreational physical activities were assigned to the 'moderate/vigorous physical activity' group. The socioeconomic factors included marital status, education, household income, health insurance, and healthcare utilization over the past 1 year. Marital status was divided into two groups: married or living with partner, and the rest.
Education level was classified into three categories of less than high school, high school or General Education Development (GED), and some college or more. Household income was summarized into a binary variable indicating an annual income of US\$20 000 or more or less than US\$20 000 since many households only reported whether their income was below or above US\$20 000. Six hundred and ninety-six subjects with missing household income information were designated as an unknown group. Selfreported health insurance status was also included. The reported number of healthcare utilizations over the past year was divided into three groups of none, one to three, and four or more. These numbers did not include overnight hospitalizations, visits to hospital emergency rooms, home visits, or telephone calls.

\section{Statistical analysis}

In this study, descriptive statistics were used to understand the general demographic characteristics. Multivariable logistic regression analyses and $\chi^{2}$ tests were used to identify the associations between the independent and dependent variables. The independent variables of interest were the depressive symptom severity groups of none, mild, moderate, moderately severe, and severe according to the PHQ-9 score. The four dependent variables of interest were prevalence of diabetes, patients' awareness of having diabetes, whether the patient was receiving treatment for diabetes, and whether the patient had adequate control of diabetes. Data were weighted to the non-institutionalized US population using sampling weights (WTMEC2YR/3), considering the PHQ-9 survey was taken at the Mobile Examination Center (MEC) 
and the diabetic outcomes of our interest were operationally defined dependent variables as the union of criteria including MEC data. In exploring the above associations, three models with expanding adjustment were used. The first model was adjusted for the basic demographic factors only. The second model was adjusted for demographic and behavioral factors. Finally, the third model included all of the covariates, adding socioeconomic factors to the second model. We also confirmed there is absence of multicollinearity between covariates by checking the generalized variance inflation factor. Statistical analysis was executed using R V.4.0.4 (2020-1010) and RStudio V.1.3.1093 (2020, The R Foundation for Statistical Computing).

\section{RESULTS}

\section{Characteristics of the study population by depressive} symptom severity

The general characteristics of the weighted study population are presented in table 1 , stratified by severity of depressive symptoms. Of the total participants representing 205446326 non-institutionalized US population, $23 \%$ reported depressive symptoms that were mild or more severe. Consistent with previous studies on demographic factors associated with depression, groups with depressive symptoms included more women $(66.2 \%$ in moderate, $66.3 \%$ in moderately severe, $57.6 \%$ in severe groups vs $47.0 \%$ in the none group), fewer individuals who were married or living with partner $(44.1 \%$ in the severe group vs $65.8 \%$ in the none group), ${ }^{23}$ fewer Asians ( $1.4 \%$ in the severe group vs $5.3 \%$ in the none group),${ }^{24}$ and more obese individuals $(48.7 \%$ in moderate, $53.2 \%$ in moderately severe, $42.8 \%$ in severe groups vs $35.6 \%$ in the none group).$^{25}$ Moreover, as depressive symptom severity worsened, the proportion of smoker/ex-smoker increased, while the proportion of participants who reported moderate to vigorous physical activity gradually decreased. Similar to previous studies, people with household income below US\$20 000 accounted for $11.4 \%$ in the none group and increased up to $29 \%$ in the severe group. ${ }^{23}$ Predictably, as depressive symptom severity became greater, the proportion of participants who used healthcare services four or more times in the past 1 year steadily increased from $32.6 \%$ in the none group to $63.6 \%$ in the severe group.

\section{Prevalence, awareness, treatment, and control of diabetes by depressive symptom severity}

Table 2 demonstrates the relationship between severity of depressive symptoms and our outcomes of interest. The odds of having diabetes (prevalence of diabetes) increased with worsening depressive symptom severity in every model ( $\mathrm{p}$ value for trend $<0.001$ in models 1 and 2, and 0.003 in model 3). Adjusting for age, sex, and race/ ethnicity, individuals with mild, moderate, moderately severe, and severe depressive symptoms had significantly increased risk of having diabetes mellitus compared with those without depression $(57 \%, 105 \%, 127 \%$, and $114 \%$, respectively). Such statistically significant increases in the prevalence of diabetes with worsening depressive symptoms were consistently observed after additionally adjusting for behavioral factors in model 2.

With regard to patients' own awareness of having diabetes, worsening depressive symptoms were associated with increased awareness of diabetes. Among those with diabetes, only $71.3 \%$ of patients with diabetes with no depressive symptoms responded that they were aware of their diagnosis of diabetes, whereas $84.5 \%$ and $86.2 \%$ of patients with diabetes in moderately severe and severe depressive symptom groups acknowledged their diabetic conditions. In the same manner, the odds of being aware of diabetes diagnosis continuously increased as depressive symptom severity escalated ( $\mathrm{p}$ value for trend 0.002 , $<0.001$, and 0.006 in models 1,2 , and 3). Specifically, in model 1 , those with mild, moderate, moderately severe, and severe depressive symptoms were $1.47,1.26,2.43$, and 3.12 times more likely to be aware of their diabetes compared with those in the none group, although this was not statistically significant in the moderate and severe groups.

Patients with depressive symptoms were less likely to receive treatment for diabetes despite having increased awareness of their diagnoses. Only $50.1 \%$ of patients with diabetes with severe depressive symptoms received treatment for their diabetes, compared with $79.3 \%$ of patients with diabetes with no depressive symptoms receiving treatment. In addition, patients with diabetes with increasing depressive symptom severity were also significantly less likely to have adequate control of their diabetes compared with those with no depressive symptoms ( $\mathrm{p}$ value for trend $0.007,0.028$, and 0.022 in models 1,2 , and 3 ).

In additional subgroup analyses by gender and ethnicity, all subgroups demonstrated the overall tendency of increasing prevalence and awareness of diabetes with worsening depressive symptoms. The proportion of patients receiving no diabetes treatments was especially high among men and ethnic minorities, while the proportion of patients with uncontrolled diabetes was more pronounced among women and white.

\section{Unhealthy behaviors by depressive symptom severity among those with diabetes}

To investigate the factors associated with lower rates of diabetes treatment and control despite increasing awareness among patients with depressive symptoms, we conducted a subgroup analysis focusing on the presence of unhealthy behaviors by depressive symptom severity. Overall, patients with depressive symptoms were significantly more likely to be obese $(74.9 \%$ in moderate, $80.1 \%$ in moderately severe, $65.9 \%$ in severe vs $57.4 \%$ in the none group). Patients with severe depressive symptoms were also significantly more likely to be ever-smokers $(68.8 \%$ vs $48.2 \%)$ and be physically inactive $(83.9 \%$ vs $56.5 \%)$ compared with those with no depressive symptoms. 
Table 1 General characteristics of the weighted study population by depressive symptom severity

\begin{tabular}{|c|c|c|c|c|c|c|}
\hline \multirow[b]{2}{*}{ Estimated proportion (\%) } & \multicolumn{5}{|c|}{ Depressive symptom severity* } & \multirow[b]{2}{*}{$P$ value } \\
\hline & $\begin{array}{l}\text { None } \\
0-4\end{array}$ & $\begin{array}{l}\text { Mild } \\
5-9\end{array}$ & $\begin{array}{l}\text { Moderate } \\
10-14\end{array}$ & $\begin{array}{l}\text { Moderately severe } \\
15-19\end{array}$ & $\begin{array}{l}\text { Severe } \\
20 \text { and higher }\end{array}$ & \\
\hline Total (n)† & 157949112 & 31099302 & 10085455 & 4280562 & 2031895 & \\
\hline \multicolumn{7}{|l|}{ Age } \\
\hline 20-39 & 35.5 & 33.4 & 34 & 30.8 & 34.5 & 0.032 \\
\hline $40-59$ & 36 & 39.9 & 39.3 & 43.8 & 47.7 & \\
\hline $60-79$ & 24.1 & 21.6 & 23.8 & 21.7 & 14.3 & \\
\hline$\geq 80$ & 4.4 & 5.1 & 2.9 & 3.6 & 3.5 & \\
\hline \multicolumn{7}{|l|}{ Sex } \\
\hline Male & 52.4 & 41.5 & 33.8 & 33.7 & 42.4 & $<0.001$ \\
\hline Female & 47.6 & 58.5 & 66.2 & 66.3 & 57.6 & \\
\hline \multicolumn{7}{|l|}{ Race/ethnicity } \\
\hline White & 67.6 & 65.6 & 64.8 & 66.1 & 58.2 & $<0.001$ \\
\hline Black & 10.4 & 12.7 & 13 & 11.8 & 10.7 & \\
\hline Mexican Hispanic & 8.4 & 8.7 & 7.1 & 8.2 & 5.5 & \\
\hline Other Hispanic & 5.6 & 5.9 & 7.3 & 9.4 & 13.7 & \\
\hline Asian & 5.3 & 4 & 2.4 & 0.6 & 1.4 & \\
\hline Others & 2.8 & 3.2 & 5.3 & 3.8 & 10.5 & \\
\hline \multicolumn{7}{|l|}{ BMI $\left(\mathrm{kg} / \mathrm{m}^{2}\right) \ddagger$} \\
\hline Underweight & 1.2 & 2.2 & 1.9 & 2 & 1.5 & $<0.001$ \\
\hline Normal & 28.9 & 23.1 & 24.7 & 16.5 & 28.5 & \\
\hline Overweight & 33.6 & 31.4 & 23.6 & 26.9 & 27 & \\
\hline Obese & 35.6 & 42.5 & 48.7 & 53.2 & 42.8 & \\
\hline Unknown & 0.7 & 0.9 & 1.2 & 1.4 & 0.2 & \\
\hline \multicolumn{7}{|l|}{ Smoking } \\
\hline Smoker/ex-smoker & 41.2 & 51.7 & 60.5 & 62.6 & 69 & $<0.001$ \\
\hline Never & 58.8 & 48.3 & 39.5 & 37.4 & 31 & \\
\hline \multicolumn{7}{|l|}{ Alcohol } \\
\hline Binge drinking & 32.4 & 34.6 & 33.6 & 28.4 & 36.7 & 0.296 \\
\hline No & 67.6 & 65.4 & 66.4 & 71.6 & 63.3 & \\
\hline \multicolumn{7}{|l|}{ Physical activity } \\
\hline Moderate/vigorous activity & 58.4 & 47.7 & 36.9 & 34.9 & 28.4 & $<0.001$ \\
\hline No & 41.6 & 52.3 & 63.1 & 65.1 & 71.6 & \\
\hline \multicolumn{7}{|l|}{ Marital status } \\
\hline Married/living with partner & 65.8 & 55.4 & 44.6 & 47.4 & 44.1 & $<0.001$ \\
\hline Other & 34.2 & 44.6 & 55.4 & 52.6 & 55.9 & \\
\hline \multicolumn{7}{|l|}{ Education } \\
\hline Less than high school & 13.1 & 17.2 & 22 & 30 & 25.9 & $<0.001$ \\
\hline $\begin{array}{l}\text { High school or General } \\
\text { Education Development } \\
\text { (GED) }\end{array}$ & 20 & 23.8 & 23.9 & 30.5 & 22.7 & \\
\hline Some college or more & 66.9 & 58.9 & 54.1 & 39.5 & 51.4 & \\
\hline \multicolumn{7}{|l|}{ Income (household, US\$) } \\
\hline$<20000$ & 11.4 & 18.2 & 28 & 31.6 & 29 & $<0.001$ \\
\hline$\geq 20000$ & 85 & 78.1 & 68.8 & 64.4 & 67.7 & \\
\hline Unknown & 3.5 & 3.7 & 3.2 & 4 & 3.3 & \\
\hline
\end{tabular}


Table 1 Continued

\begin{tabular}{|c|c|c|c|c|c|c|}
\hline \multirow[b]{2}{*}{ Estimated proportion (\%) } & \multicolumn{5}{|c|}{ Depressive symptom severity* } & \multirow[b]{2}{*}{$P$ value } \\
\hline & $\begin{array}{l}\text { None } \\
0-4\end{array}$ & $\begin{array}{l}\text { Mild } \\
5-9\end{array}$ & $\begin{array}{l}\text { Moderate } \\
10-14\end{array}$ & $\begin{array}{l}\text { Moderately severe } \\
15-19\end{array}$ & $\begin{array}{l}\text { Severe } \\
20 \text { and higher }\end{array}$ & \\
\hline Covered & 84.2 & 80.3 & 79.2 & 77.5 & 78.9 & $<0.001$ \\
\hline Not covered & 15.8 & 19.7 & 20.8 & 22.5 & 21.1 & \\
\hline \multicolumn{7}{|c|}{ Healthcare utilization/past 1 year } \\
\hline None & 16.5 & 11.3 & 12.1 & 12.4 & 9.8 & $<0.001$ \\
\hline $1-3$ & 50.9 & 40.7 & 31 & 21.9 & 26.5 & \\
\hline 4 or more & 32.6 & 47.9 & 56.9 & 65.7 & 63.6 & \\
\hline
\end{tabular}

*Depressive symptom severity was based on PHQ-9 score.

†Data are weighted to the non-institutionalized US population.

fUnderweight (BMI <18.5), normal $(18.5 \leq \mathrm{BMI}<25)$, overweight $(25 \leq \mathrm{BMI}<30)$, and obese $(\mathrm{BMI} \geq 30)$.

BMI, body mass index; PHQ-9, Patient Health Questionnaire-9.

\section{CONCLUSIONS}

To our knowledge, this is the first study to evaluate the prevalence, awareness, treatment, and control of diabetes by severity of depressive symptoms. By looking at these four diabetes-related outcomes concurrently with groups of increasing depressive symptoms, our study aimed to

Table 2 Associations of depressive symptom severity with prevalence, awareness, treatment, and control of diabetes

\begin{tabular}{|c|c|c|c|c|c|c|}
\hline \multirow[b]{2}{*}{ aOR (95\% Cl) } & \multicolumn{5}{|c|}{ Depressive symptom severity* } & \multirow[b]{2}{*}{$\begin{array}{l}P \text { value for } \\
\text { trend }\end{array}$} \\
\hline & $\begin{array}{l}\text { None } \\
0-4\end{array}$ & $\begin{array}{l}\text { Mild } \\
5-9\end{array}$ & $\begin{array}{l}\text { Moderate } \\
10-14\end{array}$ & $\begin{array}{l}\text { Moderately severe } \\
15-19\end{array}$ & $\begin{array}{l}\text { Severe } \\
20 \text { and higher }\end{array}$ & \\
\hline \multicolumn{7}{|l|}{ Prevalence } \\
\hline Proportion (\%) & 13.6 & 19.1 & 22.3 & 24.1 & 22 & \\
\hline Model 1† & 1 & $1.57(1.34$ to 1.83$)$ & 2.05 (1.53 to 2.75$)$ & 2.27 (1.65 to 3.12 ) & 2.14 (1.29 to 3.56$)$ & $<0.001$ \\
\hline Model $2 \ddagger$ & 1 & $1.42(1.20$ to 1.68$)$ & 1.74 (1.30 to 2.33$)$ & 1.77 (1.31 to 2.37$)$ & 1.85 (1.08 to 3.16$)$ & $<0.001$ \\
\hline Model 3§ & 1 & $1.26(1.04$ to 1.53$)$ & 1.41 (1.04 to 1.92$)$ & 1.35 (0.99 to 1.86$)$ & $1.43(0.85$ to 2.40$)$ & 0.003 \\
\hline \multicolumn{7}{|l|}{ Awareness } \\
\hline Proportion (\%) & 71.3 & 78.2 & 74.4 & 84.5 & 86.2 & \\
\hline Model 1† & 1 & $1.47(1.05$ to 2.07$)$ & $1.26(0.74$ to 2.15$)$ & $2.43(1.27$ to 4.64$)$ & $3.12(0.85$ to 11.38$)$ & 0.002 \\
\hline Model $2 \ddagger$ & 1 & 1.53 (1.10 to 2.13$)$ & 1.33 (0.79 to 2.24$)$ & 2.59 (1.36 to 4.94$)$ & $3.36(0.92$ to 12.26$)$ & $<0.001$ \\
\hline Model 3§ & 1 & 1.48 (1.06 to 2.06$)$ & 1.17 (0.68 to 2.04$)$ & 2.17 (1.13 to 4.15$)$ & 2.82 (0.66 to 12.02$)$ & 0.006 \\
\hline \multicolumn{7}{|l|}{ Treatment } \\
\hline Proportion (\%) & 79.3 & 76.5 & 75.7 & 84 & 50.1 & \\
\hline Model 1† & 1 & $0.88(0.61$ to 1.26$)$ & $0.93(0.59$ to 1.46$)$ & 1.63 (0.85 to 3.11$)$ & $0.33(0.16$ to 0.67$)$ & 0.326 \\
\hline Model $2 \ddagger$ & 1 & 0.83 (0.59 to 1.17$)$ & 0.85 (0.54 to 1.32$)$ & 1.45 (0.75 to 2.83$)$ & $0.33(0.16$ to 0.66$)$ & 0.181 \\
\hline Model 3§ & 1 & 0.79 (0.55 to 1.13$)$ & 0.75 (0.48 to 1.17$)$ & 1.23 (0.60 to 2.55$)$ & $0.25(0.11$ to 0.55$)$ & 0.071 \\
\hline \multicolumn{7}{|c|}{ Controlled ${ }^{\star \star}(\mathrm{HbA} 1 \mathrm{c}<7 \%)$} \\
\hline Proportion (\%) & 51.3 & 48.1 & 48.9 & 41.8 & 32.5 & \\
\hline Model 1† & 1 & 0.81 (0.62 to 1.06$)$ & 0.85 (0.57 to 1.28$)$ & 0.49 (0.25 to 0.95$)$ & $0.56(0.27$ to 1.19$)$ & 0.007 \\
\hline Model 2‡ & 1 & 0.85 (0.64 to 1.13$)$ & 0.94 (0.63 to 1.40$)$ & $0.52(0.27$ to 0.98$)$ & $0.61(0.31$ to 1.20$)$ & 0.028 \\
\hline Model $3 \S$ & 1 & 0.83 (0.63 to 1.10$)$ & $0.92(0.62$ to 1.37$)$ & $0.51(0.27$ to 0.98$)$ & $0.57(0.29$ to 1.11$)$ & 0.022 \\
\hline
\end{tabular}

Statistically significant results are written in bold $(p<0.05)$.

Data are weighted to non-institutionalized US population.

Multivariate logistic regression analysis was used.

${ }^{*}$ Depressive symptom severity was based on PHQ-9 score.

†Adjusted for age, sex, and race/ethnicity.

$\ddagger$ Adjusted for age, sex, race/ethnicity, body mass index, smoking, alcohol consumption, and physical activity.

§Adjusted for age, sex, race/ethnicity, body mass index, smoking, alcohol consumption, physical activity, marital status, education, household income, health insurance, and healthcare utilization.

१Among participants with diabetes and available treatment data.

${ }^{*}$ Among participants with diabetes and available $\mathrm{HbA} 1 \mathrm{c}$ data.

aOR, adjusted OR; HbA1c, glycated hemoglobin; PHQ-9, Patient Health Questionnaire-9. 
identify patient groups that need special attention and also highlight areas in need of improvement in caring for patients with diabetes and depression. In our study, as depressive symptom severity worsened, the prevalence and self-awareness of diabetes increased, but the treatment and control of diabetes decreased despite the higher degree of awareness. This discrepancy between awareness and management outcomes of diabetes emphasizes that currently the postdiagnostic approaches for those with depression and diabetes are not sufficient to achieve optimal diabetes control, especially among those with severe depressive symptoms. This suggests that while the current screening system may be effective for the diagnosis of diabetes, there remains an unmet need for collaborative and individualized care for patients with diabetes with severe depression following their diagnoses. As the burden of both diabetes and depression continues to rise, ${ }^{12}$ the results of our study emphasize the importance of identifying and focusing our public health resources on the particular subgroup of patients who suffer the most from the negative impacts of this comorbidity.

Previous studies have consistently indicated positive associations between depression and diabetes (diagnosed or undiagnosed) in a variety of study settings. ${ }^{48}$ Our study also confirmed the positive correlation between the prevalence of diabetes and depression, and additionally found that this association becomes stronger with increasing severity of depressive symptoms. Increase in the prevalence of diabetes by depressive symptom severity can be explained through a variety of mechanisms. Holt et $a l^{8}$ proposed several different interacting pathogenic mechanisms, including clinical burden of disease, that is, psychological reactions to the diagnosis of diabetes, lifestyle factors and adherence, antidepressant medications, brain structure and function, hypothalamic-pituitaryadrenal axis dysfunction, sleep, inflammation, and environmental factors. ${ }^{8}$ Fisher $e t a l^{7}$ similarly conceptualized and emphasized studies that dealt with socioeconomic and cultural factors such as socioeconomic disparities, ethnic differences in beliefs about the causes of depression and preferences for the treatment of diabetes, migrant populations, and stigmatization. ${ }^{7}$ Of note, the intensity of the association was slightly attenuated from $24.1 \%$ in the moderately severe to $22.1 \%$ in the most severe depressive symptom group. This attenuation may be explained by the decreasing prevalence of obesity in the most severe group $(65.9 \%$ vs $74.9 \%$ and $80.1 \%$ in the moderate and moderately severe groups). Previous studies have suggested that obesity increases with worsening of depressive symptoms. ${ }^{25}{ }^{26}$ Additionally, a study showed that poor diet that was prone to causing diabetes became prominent with more severe depressive symptoms. ${ }^{27}$ However, depression could also suppress appetite depending on the changes in patients' endocrine and metabolic states, and those with decreased appetite could lose weight, ${ }^{28}$ implying a lower risk of getting diabetes.

Higher awareness of diabetes with worsening depressive symptoms can be partly attributed to more healthcare utilizations, considering that twice as many people with severe depressive symptoms used healthcare services four or more times over the past 1 year compared with those in the none group $(63.6 \%$ vs $32.4 \%$; table 1$)$. Additionally, since the use of antidepressants is linked with risk of developing type 2 diabetes, ${ }^{29}$ it is routine for providers to screen and monitor for metabolic risk factors before and after initiating antidepressants, ${ }^{30} 31$ and this may have contributed to the higher awareness of diabetes among those with severe depressive symptoms who were prescribed pharmacological interventions. However, significant $p$ value for trends (0.006) in the association between depressive symptom severity and the prevalence of diabetes after adjusting for healthcare utilization in model 3 may imply other causes such as comorbid hypochondriasis or hypochondriacal traits among those with depressive symptoms, which may have led to a higher awareness once the diagnosis of diabetes was made. ${ }^{32}$

Notably, higher awareness in those with moderately severe to severe depressive symptoms did not lead to better treatment or control outcomes, revealing an even lower rate of treatment and control of diabetes. Likewise, table 3 elaborated that more unhealthy behaviors toward diabetic management, such as obesity, smoking, and physical inactivity, ${ }^{21}$ were seen in those with depressive

Table 3 Unhealthy behaviors of study participants with diabetes by depressive symptom severity

\begin{tabular}{|c|c|c|c|c|c|c|}
\hline \multirow[b]{2}{*}{ Estimated proportion (\%) } & \multicolumn{5}{|c|}{ Depressive symptom severity* } & \multirow[b]{2}{*}{$P$ value } \\
\hline & $\begin{array}{l}\text { None } \\
0-4\end{array}$ & $\begin{array}{l}\text { Mild } \\
5-9\end{array}$ & $\begin{array}{l}\text { Moderate } \\
10-14\end{array}$ & $\begin{array}{l}\text { Moderately severe } \\
15-19\end{array}$ & $\begin{array}{l}\text { Severe } \\
20 \text { and higher }\end{array}$ & \\
\hline Total (n)† & 21529750 & 5931984 & 2246573 & 1033388 & 447321 & \\
\hline Obesity (BMI $\geq 30)$ & 57.4 & 64.7 & 74.9 & 80.1 & 65.9 & $<0.001$ \\
\hline Ever-smokers & 48.2 & 55.5 & 61.3 & 58.9 & 68.8 & 0.001 \\
\hline Binge drinking & 17.7 & 17.5 & 17.3 & 19.1 & 19.8 & 0.997 \\
\hline Physical inactivity & 56.5 & 67.4 & 73.6 & 67.3 & 83.9 & $<0.001$ \\
\hline
\end{tabular}

$\chi^{2}$ test was used.

*Depressive symptom severity was based on PHQ-9 score.

†Data are weighted to the non-institutionalized US population.

BMI, body mass index; PHQ-9, Patient Health Questionnaire-9. 
symptoms. Previous studies also pointed out that depressive symptoms can lower the treatment and control of diabetes by non-adherence to medications and poor diet. ${ }^{33}$ Also, these results imply that current care was not sufficient to support patients with this comorbidity even after making the correct diagnosis, and the unhealthy behaviors of the comorbid population were not properly mitigated.

Our study suggests that an integrated care model for depression and diabetes-for both mental and physical health-should be implemented to satisfy the unmet needs of this comorbid population. First, from a public health perspective, it is important to reconsider the currently developing approaches for diabetes care to incorporate depression management. Although there have been ongoing efforts such as chronic care models (CCMs) and patient-centered medical homes (PCMHs) to provide holistic care for chronic diseases including diabetes in primary care settings, ${ }^{34}{ }^{35}$ limited numbers of PCMHs or CCMs for diabetes care incorporated depression screening and management. ${ }^{35} 36$ Moreover, there were concerns that CCMs in general were devised to meet the healthcare system's goals, not patient work or practical resources, and mainly focused on diseasespecific outcomes or healthcare utilization, and thus were particularly insufficient to support patients with multimorbidity. ${ }^{37}$ To resolve this challenge, Boehmer $e t$ $a l^{37}$ suggested applying minimally disruptive medicine, which is aimed at reducing patient work and improving patients' capacity, to the current CCMs. Therefore, a future approach to address the existing and evolving needs of the comorbid population with diabetes and depression could be the combination of the currently developing CCMs for different conditions and the recent successful attempts of collaborative care for diabetes and depression. $^{13}$

Alongside its public health implications, our study also has several important clinical implications for the current primary care practice in the USA. First, primary care physicians caring for patients with either diabetes or depression should screen patients for other conditions. The US Preventive Services Task Force currently recommends depression screening in general adult population (age 18 or older) and screening for abnormal blood glucose in adults aged 40-70 years who are overweight and obese. ${ }^{38}{ }^{39}$ In addition to this, primary physicians should bear in mind the risk of comorbidity and take a thorough patient history to ask and counsel about personal challenges such as diet, physical activity, medication management, and psychological stress. Finally, active consultations with specialists need to be performed, integrating behavioral health professionals as was suggested in the PCMHs for diabetes. ${ }^{35}$ As it may often be challenging for patients to be referred to specialists due to insurance coverage and socioeconomic vulnerabilities, it is crucial that primary care physicians are sufficiently trained to perform competent initial care for both diabetes and depression.
Our study must be interpreted in the context of its limitations. First, as a cross-sectional analysis, the direction of causality of the relationships remains unclear. Second, we used PHQ-9 score as the only variable to determine depressive symptom severity in NHANES, but there have been arguments that the PHQ-9 may overestimate depressive symptom severity. ${ }^{40}$ Third, since the sample size of the severely depressed group was relatively small, the associations in that group, presented particularly in online supplemental data, could be less accurate. Further research should be conducted with other modes of measuring depressive symptom severity and with a larger sample population to sufficiently represent the severely depressed group.

In summary, this study highlights the strong associations between depressive symptom severity and the prevalence, awareness, management, and control of diabetes among patients with comorbid diabetes and depression, and emphasizes the crucial need for improvements in postdiagnostic care for patients with severe depression and diabetes. Current care targeted for either diabetes or depression management still remains fragmented and mostly focuses on the screening of the other condition. Considering the chronic burden of diabetes and depression, postdiagnostic, long-term collaborative care for these conditions should be implemented particularly in treating patients with poorly controlled diabetes.

\section{Author affiliations}

${ }^{1}$ Department of Biomedical Sciences, Seoul National University Hospital, Seoul, Korea (the Republic of)

${ }^{2}$ Department of Family Medicine, Seoul National University Hospital, Seoul, Korea (the Republic of)

${ }^{3}$ Division of Gastroenterology and Hepatology, Mayo Clinic in Rochester, Rochester, Minnesota, USA

${ }^{4}$ Department of Psychiatry, Yale University School of Medicine, New Haven,

Connecticut, USA

${ }^{5}$ Department of Family Medicine, Korea University Guro Hospital, Seoul, Korea (the Republic of)

${ }^{6}$ Department of Family Medicine, Gachon University Gil Medical Center, Incheon, Korea (the Republic of)

${ }^{7}$ Department of Family Medicine, Jeju National University Hospital, Jeju, Korea (the Republic of)

Acknowledgements We wish to thank Jerome Delamater for his assistance with correction of English grammar and wording of the final manuscript, and also thank Ji Hyung Ryu for her advice on R language used in this study.

Contributors $\mathrm{JL}$ developed the question, researched the data, and wrote the manuscript. KHK, JSS, and GL helped develop the study design and presentations and reviewed/edited the manuscript. KHK, JCA, JAK, SJC, and YHO contributed to the discussion and reviewed/edited the manuscript. SMP also researched the data and cowrote the manuscript. JL and SMP take responsibility for the content of the article.

Funding The authors have not declared a specific grant for this research from any funding agency in the public, commercial or not-for-profit sectors.

Competing interests None declared.

Patient consent for publication Not required.

Ethics approval The required ethical approval for the use of the NHANES survey data from years 2011 to 2016 was obtained from the National Center for Health Statistics (NCHS) Research Ethics Review Board (ERB) through Protocol Number \#2011-17. All participants included in this study provided written informed consent. The information collected by the NCHS is kept and treated with strict confidentiality bound to federal law. 
Provenance and peer review Not commissioned; externally peer reviewed.

Data availability statement Data used in this study are available in a public, open access repository at https://www.cdc.gov/nchs/nhanes/index.htm. Data are provided by the Centers for Disease Control and Prevention.

Supplemental material This content has been supplied by the author(s). It has not been vetted by BMJ Publishing Group Limited (BMJ) and may not have been peer-reviewed. Any opinions or recommendations discussed are solely those of the author(s) and are not endorsed by BMJ. BMJ disclaims all liability and responsibility arising from any reliance placed on the content. Where the content includes any translated material, BMJ does not warrant the accuracy and reliability of the translations (including but not limited to local regulations, clinical guidelines, terminology, drug names and drug dosages), and is not responsible for any error and/or omissions arising from translation and adaptation or otherwise.

Open access This is an open access article distributed in accordance with the Creative Commons Attribution Non Commercial (CC BY-NC 4.0) license, which permits others to distribute, remix, adapt, build upon this work non-commercially, and license their derivative works on different terms, provided the original work is properly cited, appropriate credit is given, any changes made indicated, and the use is non-commercial. See: http://creativecommons.org/licenses/by-nc/4.0/.

ORCID iDs

Gyeongsil Lee http://orcid.org/0000-0003-1910-9658

Sang Min Park http://orcid.org/0000-0002-7498-4829

\section{REFERENCES}

1 CDC. National diabetes statistics report 2020 estimates of diabetes and its burden in the United States, 2020.

2 SAMHSA. Key substance use and mental health indicators in the United States: results from the 2019 national survey on drug use and health, 2020.

3 Anderson RJ, Freedland KE, Clouse RE, et al. The prevalence of comorbid depression in adults with diabetes: a meta-analysis. Diabetes Care 2001;24:1069-78.

4 Mezuk B, Eaton WW, Albrecht S, et al. Depression and type 2 diabetes over the lifespan: a meta-analysis. Diabetes Care 2008;31:2383-90.

5 Golden SH, Lazo M, Carnethon M, et al. Examining a bidirectional association between depressive symptoms and diabetes. JAMA 2008;299:2751-9.

6 Roy T, Lloyd CE. Epidemiology of depression and diabetes: a systematic review. J Affect Disord 2012;142 Suppl:S8-21.

7 Fisher EB, Chan JCN, Nan H, et al. Co-Occurrence of diabetes and depression: conceptual considerations for an emerging global health challenge. J Affect Disord 2012;142:S56-66.

8 Holt RIG, de Groot M, Golden SH. Diabetes and depression. Curr Diab Rep 2014;14:491.

9 Lustman PJ, Anderson RJ, Freedland KE, et al. Depression and poor glycemic control: a meta-analytic review of the literature. Diabetes Care 2000;23:934-42.

10 de Groot M, Anderson R, Freedland KE, et al. Association of depression and diabetes complications: a meta-analysis. Psychosom Med 2001;63:619-30.

11 GOLDNEY RD, Diabetes M. Depression, and quality of life. Diabetes Care 2004;27.

12 Katon WJ, Lin EHB, Von Korff M, et al. Collaborative care for patients with depression and chronic illnesses. N Engl J Med 2010;363:2611-20.

13 Huang Y, Wei X, Wu T, et al. Collaborative care for patients with depression and diabetes mellitus: a systematic review and metaanalysis. BMC Psychiatry 2013;13:260.

14 Rossom RC, Solberg LI, Magnan S, et al. Impact of a national collaborative care initiative for patients with depression and diabetes or cardiovascular disease. Focus 2017;15:324-32.

15 Gary TL, Crum RM, Cooper-Patrick L, et al. Depressive symptoms and metabolic control in African-Americans with type 2 diabetes. Diabetes Care 2000;23:23-9.

16 Briganti CP, Silva MT, Almeida JVde, et al. Association between diabetes mellitus and depressive symptoms in the Brazilian population. Rev Saude Publica 2018;53: :5.
17 Wang Q, Zhang X, Fang L, et al. Prevalence, awareness, treatment and control of diabetes mellitus among middle-aged and elderly people in a rural Chinese population: a cross-sectional study. PLOS One 2018:13:e0198343.

18 McDonald M, Hertz RP, Unger AN, et al. Prevalence, awareness, and management of hypertension, dyslipidemia, and diabetes among United States adults aged 65 and older. J Gerontol A Biol Sci Med Sci 2009;64:256-63.

19 Kaiser A, Vollenweider P, Waeber G, et al. Prevalence, awareness and treatment of type 2 diabetes mellitus in Switzerland: the CoLaus study. Diabet Med 2012;29:190-7.

20 Kroenke K, Spitzer RL, Williams JB. The PHQ-9: validity of a brief depression severity measure. J Gen Intern Med 2001;16:606-13.

21 Ada, Standards of Care 2020.pdf. Diabetes Care 2020:43.

22 National Institute on alcohol abuse and alcoholism, overview of alcohol consumption. Drinking Levels Defined 2020.

23 Akhtar-Danesh N, Landeen J. Relation between depression and sociodemographic factors. Int J Ment Health Syst 2007;1:4.

24 Jackson JS. The intersection of race, ethnicity, immigration, and cultural influences on the nature and distribution of mental disorders: an examination of major depression, in the conceptual evolution of DSM-5. Arlington, VA, US: American Psychiatric Publishing, Inc, 2011: 267-85.

25 Luppino FS, de Wit LM, Bouvy PF, et al. Overweight, obesity, and depression: a systematic review and meta-analysis of longitudinal studies. Arch Gen Psychiatry 2010;67:220-9.

26 Richardson LP, Garrison MM, Drangsholt M, et al. Associations between depressive symptoms and obesity during puberty. Gen Hosp Psychiatry 2006;28:313-20.

27 Appelhans BM, Whited MC, Schneider KL, et al. Depression severity, diet quality, and physical activity in women with obesity and depression. J Acad Nutr Diet 2012;112:693-8.

28 Simmons WK, Burrows K, Avery JA, et al. Appetite changes reveal depression subgroups with distinct endocrine, metabolic, and immune states. Mol Psychiatry 2020;25:1457-68.

29 Yoon JM, Cho E-G, Lee H-K, et al. Antidepressant use and diabetes mellitus risk: a meta-analysis. Korean J Fam Med 2013;34:228-40.

30 Mclntyre RS, Park KY, Law CWY, et al. The association between conventional antidepressants and the metabolic syndrome: a review of the evidence and clinical implications. CNS Drugs 2010;24:741-53

31 Dodd S, Malhi GS, Tiller J, et al. A consensus statement for safety monitoring guidelines of treatments for major depressive disorder. Aust N Z J Psychiatry 2011;45:712-25.

32 Magariños M, Zafar U, Nissenson K, et al. Epidemiology and treatment of hypochondriasis. CNS Drugs 2002;16:9-22.

33 Gonzalez JS, Peyrot M, McCarl LA, et al. Depression and diabetes treatment nonadherence: a meta-analysis. Diabetes Care 2008;31:2398-403.

34 Bodenheimer T, Wagner EH, Grumbach K. Improving primary care for patients with chronic illness. JAMA 2002;288:1775-9.

35 Bojadzievski T, Gabbay RA. Patient-Centered medical home and diabetes. Diabetes Care 2011;34:1047-53.

36 Baptista DR, Wiens A, Pontarolo R, et al. The chronic care model for type 2 diabetes: a systematic review. Diabetol Metab Syndr 2016;8: :7.

37 Boehmer KR, Abu Dabrh AM, Gionfriddo MR, et al. Does the chronic care model meet the emerging needs of people living with multimorbidity? A systematic review and thematic synthesis. PLOS One 2018:13:e0190852.

38 Siu AL, U S Preventive Services Task Force. Screening for abnormal blood glucose and type 2 diabetes mellitus: U.S. preventive services Task force recommendation statement. Ann Intern Med 2015;163:861-8.

39 Siu AL, Bibbins-Domingo K, US Preventive Services Task Force (USPSTF), et al. Screening for depression in adults: US preventive services Task force recommendation statement. JAMA 2016;315:380-7.

40 Levis B, Benedetti A, loannidis JPA, et al. Patient health Questionnaire-9 scores do not accurately estimate depression prevalence: individual participant data meta-analysis. J Clin Epidemiol 2020;122:115-28. 